\title{
Rancang Bangun DC Chopper Satu Kuadran Berbasis Simulink Matlab
}

\author{
Azhar Ihsan ${ }^{1}$, Muldi Yuhendri² \\ 1,2 Jurusan Teknik Elektro, Fakultas Teknik, Universitas Negeri Padang \\ JL. Prof. Dr. Hamka, Air Tawar Padang, 35132, Indonesia \\ Azarihsan0913@gmail.com¹, muldiy@ft.unp.ac.id ${ }^{2}$
}

\begin{abstract}
DC power supply is a series of electronic components that can supply DC voltage to other electronic components. Each electronic device requires a different supply voltage. Due to the wide use of this power supply, we need a system that can convert DC voltage from one voltage level to another. Then one way to convert DC voltage to other DC tension is to use a system known as DC choper. In one quadrant DC chopper system, the average value of the output voltage and current is always positive and the power always flows from the source to the load. This paper proposes a one-quadrant DC chopper based on a proportional (P) controller. The control system is implemented using an arduino mega 2560 microcontroller programmed with matlab simulink. Control system equipment is equipped with a potentiometer as a decrease in the input voltage of $200 \mathrm{VDC}$ into a voltage that varies according to the desired desired so that the output voltage remains stable. The voltage of $200 \mathrm{VDC}$, which is a high voltage, requires IGBT to make a larger current and operate in high voltage because it has better efficiency. To detect this voltage, a voltage sensor is needed which consists of two resistors valued at $330 \mathrm{~K}$ and $6.3 \mathrm{~K}$ and a current sensor is used to detect current, the current sensor used is the ACS712 current sensor. The one-quadrant DC chopper system was verified through laboratory experiments with a load resistor load. The test results show that the DC chopper one quadrant based on the proportional controller proposed in this paper has worked well. This can be seen from the output voltage produced in accordance with the desired voltage which is set through the ponthesiometer.
\end{abstract}

Keywords - DC Choper one uadrant, arduino, matlab simulink.

Abstrak-Catu daya DC merupakan serangkaian komponen elektronik yang dapat menyuplai tegangan DC ke komponen elektronik lainnya. Setiap perangkat elektronik membutuhkan tegangan suplay yang berbeda-beda. Karena penggunaan catu daya yang luas ini, diperlukan suatu sistem yang dapat mengkonversikan tegangan DC dari suatu tingkat tegangan ketingkat tegangan lainnya. Maka salah satu cara untuk mengubah tegangan DC ketegangan DC lainnya digunakan sistem yang dikenal sebagai DC choper. Pada Sistem DC choper satu kuadran nilai rata-rata tegangan keluaran dan arusnya selalu positif dan dayanya selalu mengalir dari sumber ke beban. Paper ini mengusulkan DC chopper satu kuadran berbasis kontroller proportional (P). Sistem kendali diimplementasikan dengan menggunakan mikrokontroller arduino mega 2560 yang diprogram dengan simulink matlab. Peralatan sistem kendali dilengkapi dengan potensiometer sebagai penurunan tegangan input 200 VDC menjadi tegangan yang bervariasi sesuai dengan yang diinginkan yang diinginkan agar tegangan keluaran tetap stabil. Tegangan 200 VDC yang termasuk tegangan tinggi maka dibutuhkan IGBT untuk membuat arus yang lebih besar dan beroperasi dalam tegangan tinggi karena memiliki efesiensi yang lebih baik. Untuk mendeteksi tegangan tersebut dibutuhkan sensor tegangan yang terdiri dua buah resistor yang bernilai $330 \mathrm{~K}$ dan $6,3 \mathrm{~K}$ dan sensor arus yang digunakan unyuk mendeteksi arus, sensor arus yang digunakan sensor arus ACS712. Sistem DC choper satu kuadran diverifikasikan melalui percobaan di laboratorium dengan beban load resistor. Hasil pengujian menunjukkan bahwaDC chopper satu kuadran berbasis kontroller proportional yang diusulkan dalam paper ini telah bekerja dengan baik. Hal ini dapat dilihat dari tegangan output yang dihasilkan sesuai dengan tegangan yang diinginkan yang atur melalui pontesiometer.

Kata kunci- DC Choper satu kuadran, arduino, simulink matlab

\section{Pendahuluan}

Catu daya DC merupakan serangkaian komponen elektronik yang dapat menyuplai tegangan DC ke komponen elektronik lainnya. Setiap perangkat elektronik membutuhkan tegangan supplai yang berbeda-beda, hal ini tergantung pada spesifikasi perangkat elektronik tersebut mulai dari tegangan skala rendah, tegangan skala menengah hingga tegangan skala tinggi. Seperti pada mikroprosesor, IC, motor-motor listrik dan generator, hingga transmisi listrik tegangan tinggi [1].
Catu daya semakin banyak dibutuhkan karena cara kerja yang dapat mengubah tegangan DC secara bervariasi, baik dari tegangan rendah ke Tegangan tinggi maupun sebaliknya. Metode ini harus bisa bekerja secara efektif sehingga tegangan keluarannya mempunyai mutu yang bagus [2]. Salah satu cara untuk mengkonversikan tegangan masuk menjadi tegangan output searah yang divariasikan berdasarkan perubahan duty cycle yaitu DC chopper [3]. DC Chopper adalah salah satu alat elektronika daya yang sangat berkembang saat ini, yang mana konverter ini sangat memiliki banyak fungsi di dalam 
dunia industri, salah satunya yaitu digunakan untuk mengatur kecepatan motor arus [4].

DC Chopper memiliki efesiensi yang tinggi,respon cepat dan control yang mudah [5]. Hal ini bertujuan untuk kemudahan pengendalian alat-alat elektronik di industri skala besar dan rumahan. DC chopper dapat dimanfaatkan untuk berbagai perangkat elektronika yang sesuai dengan keperluan yang penggunaannya yaitu sumber penghasil tegangan searah seperti panel surya yang keluarannya dapat dirubah menjadi lebih kecil atau lebih besar. Penelitian tentang DC choper telah dilakukan beberapa peneliti, seperti penelitian perancangan alat pratikum klasifikasi DC choper untuk mengetahui dan membedakan masing-masing gelombang keluaran dari bentuk-bentuk klasifikasi DC Choper [6]. DC chopper satu kuadran berfungsi untuk menurunkan tegangan DC. Rangkaian DC Choper bekerja dengan metode switching (pensaklaran), Sistem DC Choper satu kuadran merupakan salah satu regulator DC tipe pensaklaran nonisolated yang dapat menjawab kebutuhan akan sebuah sumber tegangan searah dengan tegangan keluaran yang variabel [7]. Pada sistem DC chopper satu kuadran nilai rata-rata tegangan keluaran dan arusnya selalu positif dan dayanya selalu mengalir dari sumber ke beban [8]. Untuk mengatur nilai tegangan keluaran menjadi lebih kecil dari nilai tegangan masukannya maka mengatur besar lebar pulsa (duty cycle) dari PWM (Pulse Width Modulation).

PWM (Pulse Width Modulation) merupakan salah satu teknik modulasi dengan cara mengubah lebar pulsa (dutty cycle) sementara nilai amplitudo dan frekuensinya tetap. Satu siklus pulsa merupakan kondisi high lalu zona transisi menuju kondisi low [9]. Lebarnya pulsa PWM akan berbanding lurus dengan amplitudo sinyal asli yang belum termodulasi. Duty Cycle merupakan rata-rata ouput yang bervariasi lebar pulsa hidup dan mati [10].

Selain itu pada perancangannya PWM analog banyak menggunakan jenis-jenis komponen elektronika untuk menentukan nilai frekuensi dan nilai duty cycle dari PWM tersebut. Supaya tegangan keluaran yang dihasilkan sesuai dengan keinginan maka duty cycle harus diatur.

Peneletian ini DC chopher satu kuadran berfungsi untuk menurunkan tegangan input 200 VDC menjadi tegangan yang diinginka. DC chopper satu kuadran terdapat satu saklar aktif (mosfet) dan satu saklar pasif (dioda) serta satu induktor dan kapsitor sedangkan Mikrokontroler Arduino Mega sebagai kontrollernya karena pada arduino mega 2560 terdapat sebuah chip jenis AVR dan boardnya sudah sangat lengkap [11] Sementara untuk pemograman mikrokontroler Arduino Mega menggunakan Simulink pada aplikasi Matlab dengan metode penguatan proposional dikarenakan memberi pengaruh lansung pada error [12]. Matlab Simulink dipilih karena lebih mudah digunakan mendesain sitem kendali [13].

\section{Metode}

Perancangan alat adalah proses pembuatan sistem dengan rencana detail dan spesifik mengenai proses pembuatannya. Pada penelitian ini penulis merancang sebuah sistem kendali tegangan dc menggunakan dc chopper satu kuadran berbasis matlab dengan kontroler proporsional dan digunakan sebuah beban load resistor. Hal pertama yang dilakukan yaitu perancangan dengan membuat blok diagram. Perancangan blok diagram dalam penelitian ini bertujuan untuk memudahkan dalam proses perancangan alat serta memudahkan dalam proses analisa dengan mengacu pada blok diagram tersebut. Berikut pada gambar 1 blok diagram sistem.

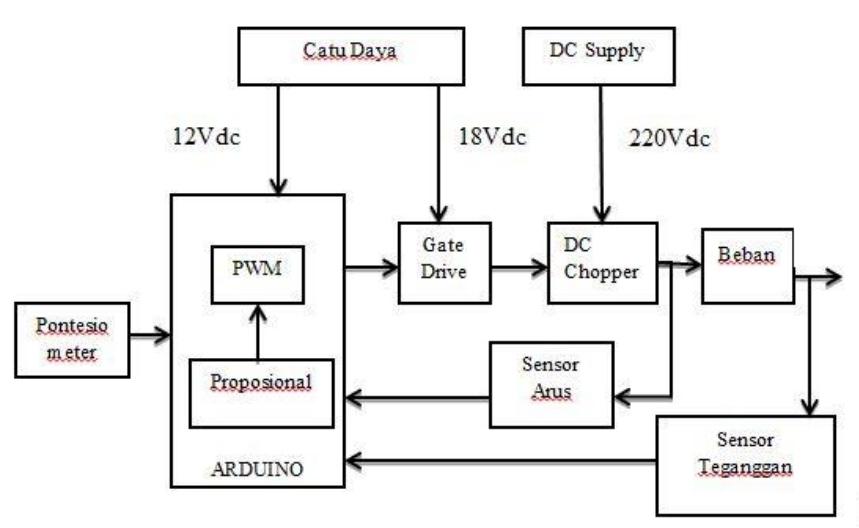

Gambar 1. Blok diagram sistem

Pada gambar 1 diatas menunjukan bahwa catu daya yang digunakan sebagai penyearah 12 VDC sebagai sumber tegangan, mikrokontroler Arduino Mega 2560 yang sebagai pusat kendali menerima input dari potensiometer yang digunakan sebagai masukan tegangan output referensi. Catu daya yang digunakan sebagai penyearah 18 VDC sebagai suplai ke rangkaian gate drive yang digunakan sebagai switching mosfet pada rangkaian DC Chopper ketika gate drive mendapatkan sinyal pulsa PWM dari mikrokontroler Arduino Mega 2560. Input dari sensor tegangan untuk mengukur tegangan keluaran DC chopper yang digunakan Arduino Mega 2560 sebagai feedback kendali tegangan Arduino. Input dari sensor arus untuk mengukur arus keluaran DC Chopper yang digunakan Arduino Mega 2560. DC Chopper yang bekerja menurunkan tegangan 200 VDC yang disuplai oleh power supply DC diberi sebuah beban laod resistor. Blok controller yang diprogram dalam Simulink Matlab serta Arduino Mega 2560 sebagai antarmuka antara Simulink Matlab dalam PC dengan hardware rangkaian.

Tegangan output DC choper satu kuadran ditentukan oleh nilai waktu switching dari sakelar daya DC choper, waktu switching saklar daya ini diatur dengan metode pulse width modulation (PWM). Waktu switching sakelar pada PWM ini ditentukan oleh lebar pulsa modulasi, dimana lebar pulsa tersebut ditentukan oleh duty cycle. 
Sakelar daya yang digunakan DC choper adalah mosfet. Gambar 2 menunjukan skema DC choper satu kuadran yang dirancang,

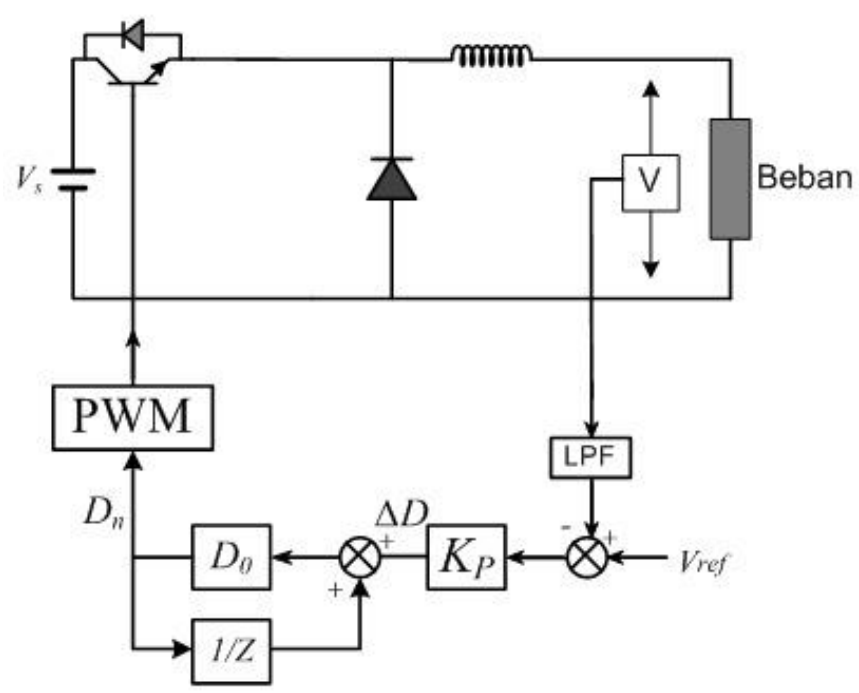

Gambar 2. Skema DC chopper satu kuadran

Pada gambar 2 menunjukkan dioda digunakan untuk mengalirkan arus yang dihasilkan induktor saat MOSFET dalam keadaan Off. Agar tegangan keluaran konstan, DC chopper satu kuadran dapat divariasikan dengan menambah rangkaian feedback (umpan balik). Tegangan referensi yang diatur oleh potensiometer akan dibandingkan dengan tegangan keluaran yang dibaca oleh sensor tegangan dan akan dikontrol oleh proposional pada program disimulink matlab, selisih antara keduanya dijadikan sebagai acuan untuk menentukan seberapa besar penambahan atau pengurangan lebar pulsa sehingga tegangan keluaran yang dihasilkan bernilai konstan.

Semakin besar lebar pulsa, maka semakin besar tegangan keluaran yang dihasilkan DC chopper satu kuadran [14]. kontoroller proporsional digunakan agar tegangan keluaran tidak akan lebih besar dari tegangan masukan DC Chopper karena proporsional ini dapat memperbaiki respon rise rime dan settling time dan memberi pengaruh lansung pada error.

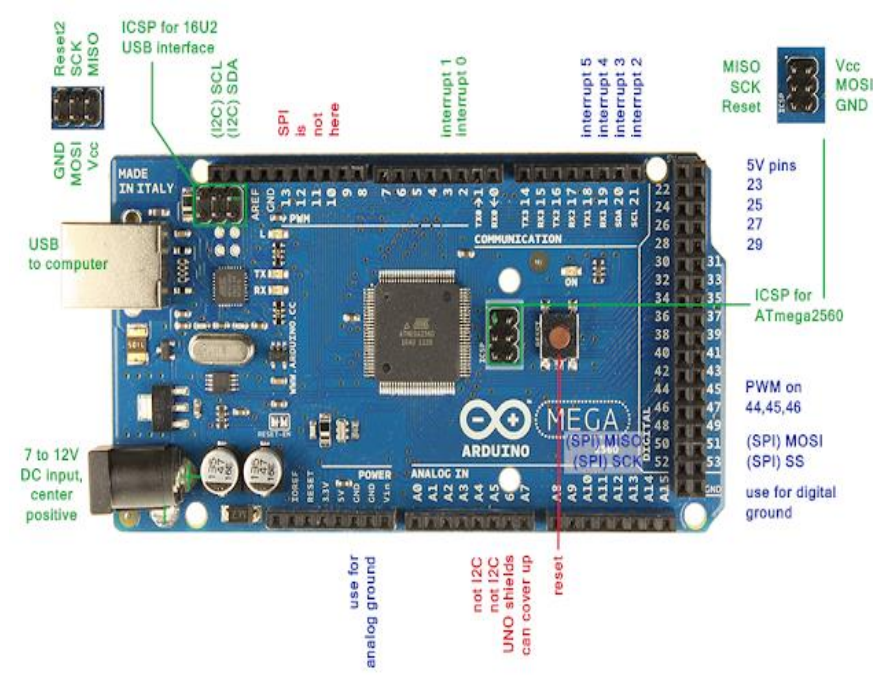

Gambar 3. Arduino mega 2560

Gambar 3 menunjukan Mikrokontroller Arduino Mega 2560 berfungsi sebagai pusat kontrol yang mengendalikan proses input dan output pada rangkaian elektronik. Ardunio Mega 2560 merupakan papan pengembangan mikrokontroller dengan menggunakan chip Atmega2560. Papan ini mempunyai 54 buah pin digital I/O pin yang 15 diantaranya dapat digunakan sebagai PWM, 16 pin analog input, serta 4 pin UART sebagai serial port hardware. Papan ini juga dilengkapi dengan sebuah oscillator 16 Mhz, sebuah port USB, power jack DC, ICSP header, serta sebuah tombol reset.

IGBT merupakan sebuah transistor yang memiliki kecepatan pensaklaran dengan frekuensi kerja yang tinggi sehingga banyak digunakan dalam rangkaian drive (pengendali motor) yang membutuhkan arus besar dalam pengoperasiannya [15]. Drive motor juga beroperasi pada tegangan yang tinggi yang membutuhkan efisiensi pensaklaran yang lebih baik, sehingga IGBT merupakan transistor yang cocok digunakan dalam rangkaian pengedali motor listrik.

Gate drive pada penelitian ini berfungsi sebagai penguat arus dan tegangan pada gelombang pulsa sehingga gelombang pulsa ini dapat memenuhi syarat untuk memicu aktifnya gate pada IGBT. Selain itu, gate drive juga berguna sebagai isolasi pengaman antara rangkaian daya dengan rangkaian kontrol. 


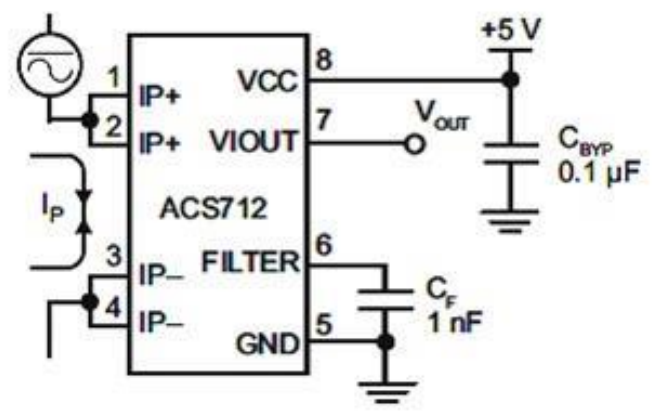

Gambar 4. sensor arus ACS712

Pada gambar 4 sensor ACS712 yang digunakan sebagai sensor pendeteki arus untuk project yang berhubungan dengan pembacaan arus. Sensor ACS712 dilengkapi dengan penguat serta mempunyai tingkat pengukuran arus hingga 5 ampere.
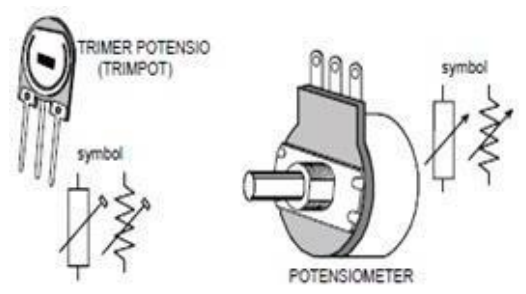

Gambar 5. potensiometer

Gambar 5 menunjukan Potensiometer digunakan sebagai pembagi tegangan variabel. Posisi wiper pada potensiometer menentukan rasio resitansi dari resistor pertama ke resistor kedua. Artinya nilai resistansi sebuah potensiometer dapat diatur sesuai dengan kebutuhan rangkaian elektronika yang akan di uji. Selain itu potensiometer juga bisa digunakan sebagai pegatur tegangan power supply (DC Generator).

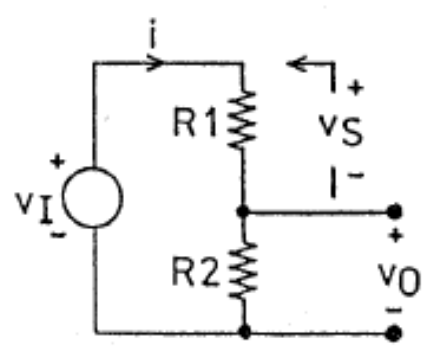

Gambar 6. skematik sensor tegangan

Gambar 6 pada R1 dan R2 diberi nilai $6,7 \mathrm{~K}$ dan 330K berikut rumus pembagi tegangan seperti dibawah ini :

$$
R 2=\frac{V o}{V i} *(R 1+R 2)
$$

Dimana :

R1 : Resistor R1

R2 : Resistor R2

$\mathrm{Vi}$ : Tegangan Input

Vo : Tagangan Output

Tegangan yang timbul dari salah satu tahanan seri tersebut adalah tahanan total dilakukan rasio (perbandingan) dari tahan dan tahanan total. Sensor tegangan (pembagi tegangan) berfungsi untuk mengukur tegangan keluaran atau masukan pada rangkaian yang digunakan sebagai acuan bagi alat kontrol untuk mengontrol lebar pulsa PWM.

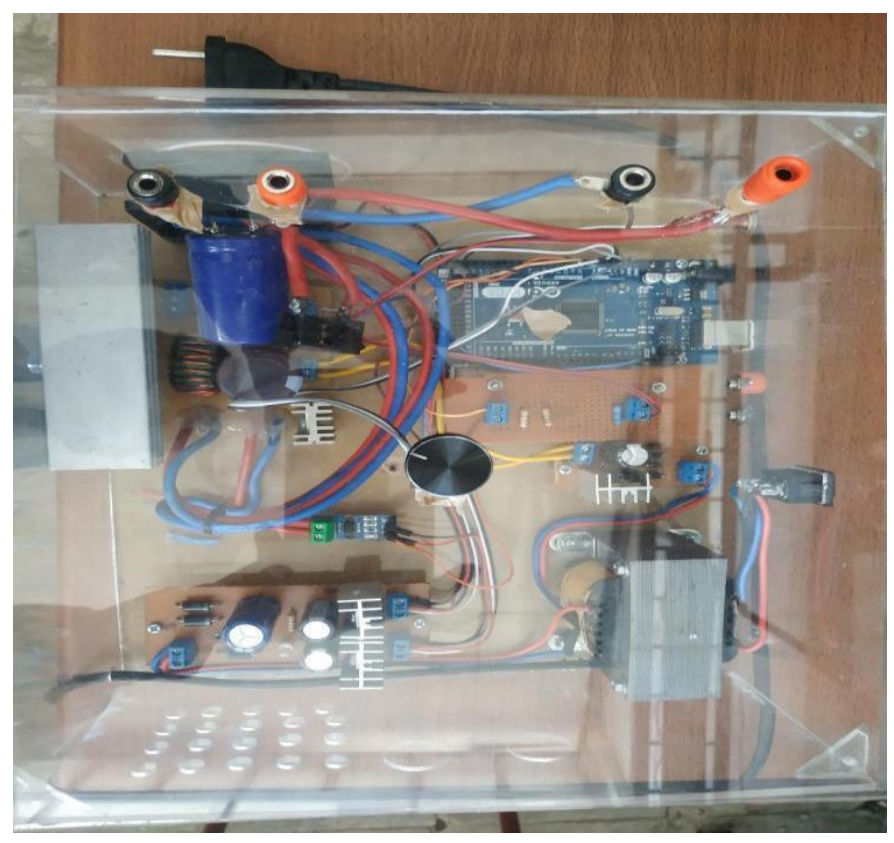

Gambar 7. Hardware DC choper satu kuadran

Pada gambar 7 hardware DC chopher satu kuadran yang sudah terdapat potensiometer,arduino mega 2560, catu daya dan rangkaian gate drive. Untuk mendapatkan pulsa PWM DC chopper satu kuadran yang sesuai dengan tegangan output yang diinginkan, maka dilakukan proses pemograman Arduino dengan simulink Matlab. Pemograman Arduino dengan simulink Matlab dimulai dengan inisialisasi port input dan output Arduino pada Simulink. Selanjutnya dilakukan pembuatan blok-blok program, seperti blok Analog input untuk untuk memasukkan nilai tegangan output referensi yang diinginkan, blok lookup table untuk mengkonversikan nilai duty cycle. Blok saturation untuk membatasi nilai duty cycle yang diizinkan, blok output PWM untuk mengkonversikan nilai duty cycle menjadi pulsa PWM dan blok scope untuk menampilkan grafik tegangan referensi dan tegangan output yang terbaca oleh sensor tegangan. Blok output PWM berisikan nomor pin PWM Arduino yang digunakan serta frekuensi switching dari PWM. Frekuensi 
switching yang digunakan untuk modulasi sakelar daya konverter dirancang sebesar $31 \mathrm{kHz}$, sedangkan pin PWM yang digunakan adalah pin 11. Pin 11 ini kemudian dihubungkan dengan rangkaian driver gate,

\section{HASIL DAN PEMBahaSAN}

Dalam melakukan pengujian pada alat ini yaitu membuat program terlebih dahulu untuk dihubungkan ke arduino setelah selesai membuat program alat dihubungkan dengan beban resistor. Untuk melihat tegangan input dan sinyal PWM alat dihubungkan ke osiloskop dan kalau melihat tegangan output dan arus serta nilai duty cycle bisa dilihat pada blok scope yang terdapat pada program Simulink matlab

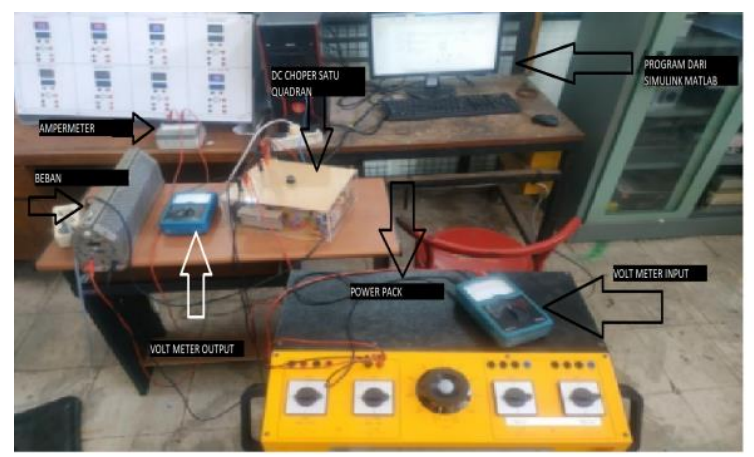

Gambar 8. Pengujian alat

Gambar 8 menunjukan pengujian alat secara keseluruhan, DC chopper satu kuadran yang dibuat pada tugas akhir ini menggunakan input dari power supply dengan tegangan 200 volt. Pengujian tegangan input dilakukan untuk memastikan tegangan yang diberi oleh power supply sudah sama dengan tegangan input yang diinginkan untuk input alat ini. Gambar 9 menunjukan pengujian dari tegangan input DC choper satu kuadran.

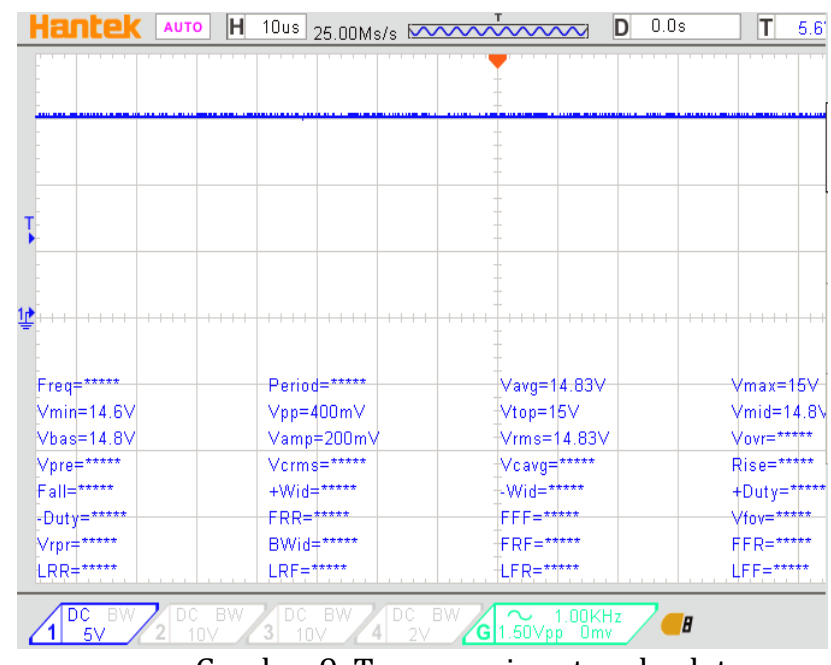

Gambar 9. Tegangan input pada alat
Rancangan DC chopper ini diimplementasikan dengan software Simulink matlab yang terdapat 3 blok analog input yaitu potensiometer dan sensor tegangan serta sensor arus yang lansung terhubung ke masing-masing pin analog arduino. Pada program ini terdapat kontrol proporsional yang bisa menambah atau mengurangi kestabilan alat serta dapat memperbaiki respon transien khususnya rise time dan settling time lalu mengurangi error steady state. Selanjutnya sebuah blok PWM digunakan untuk membangkitkan pulsa PWM pada pin 11 arduino mega 2560. Gambar 10 menunjukkan tampilan program yang terdapat pada software Simulink matlab

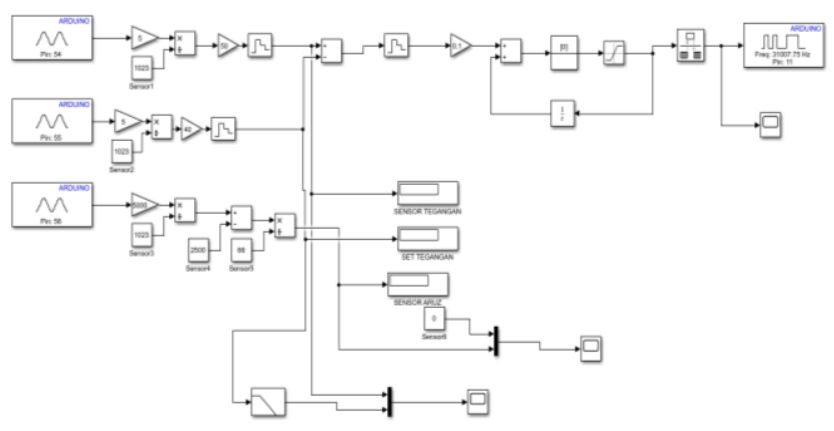

Gambar 10. Kontroller proposional pada Simulink matlab

Pada perancangan DC choper ini sinyal PWM dibangkitkan dari mikrokontroler Arduino uno dengan frekuensi $31 \mathrm{kHz}$. Pengaturan lebar pulsa PWM tersebut diatur oleh program pada arduino sesuai tegangan output referensi dari potensiometer pada pin A0 dan pin 11 sebagai keluaran dari sinyal PWM. PWM yang digunakan untuk menswitching gate MOSFET pada rangkaian DC choper. Pada gambar 11 menjelaskan tegangan referensi sebesar 50 volt yang diset menggunakan potensiometer yang diukur menggunakan osiloskop digital dengan skala grafik 5 volt/div.

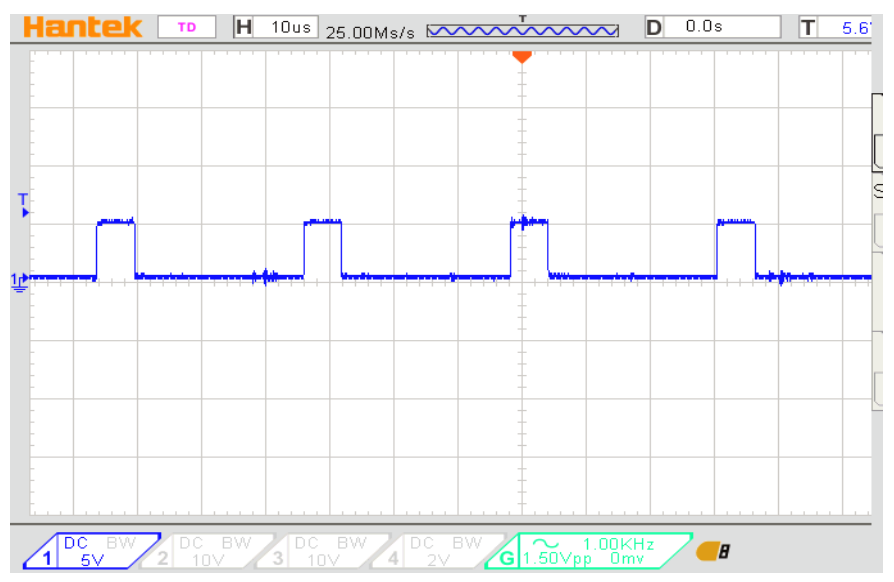

Gambar 11. Gelombang pwm pada saat tegangan referensi 50 volt 
Dalam pengujian alat ini tegangan referensi yang diset dengan potensiometer dilakukan bervariasi dan terhubung dengan pin A1 pada arduino mega 2560. Pada gambar menunjukan bahwa tegangan variasi yang dihasilkan dapat dengan jelas, bahwa tegangan outputnya lansung mengikuti tegangan referensi menunjukkan kontroler bekerja dengan baik

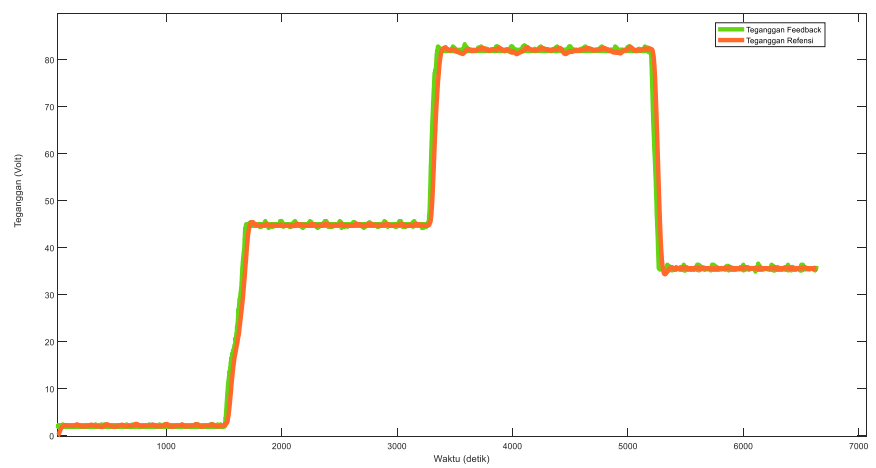

Gambar 12. Respon tegangan refensi dan tegangan output dengan Variasi Set Point

Pada gambar 12 dapat menunjukan saat tegangan referensi di set 45volt tegangan output lansung mengikuti pada waktu 3,5 detik tegangan referensi di set 83volt tegangan output lansung mengikuti dan pada waktu 5,5 detik tegangan referensi di set 35volt tegangan output lansung mengikuti.ini membuktikan bahwa pengendali proposional telah sesuai dengan semestinya.

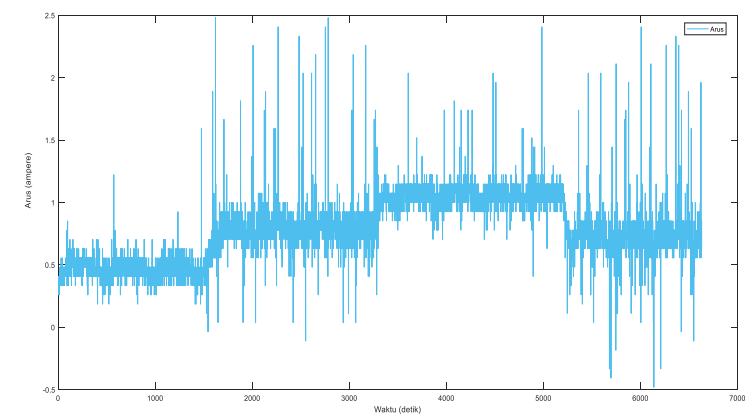

Gambar 13. Respon Arus Motor dengan Variasi Set Point

Dari gambar 13 dapat dinyatakan bahwa semakin tinggi teganggan yang ada pada gambar 12 arus juga ikut naik begitu juga sebaliknya jika tegangan turun arus juga ikut turun maka dapat disimpulkan bahwa pengendali proposional telah bekerja dengan baik. Untuk sensor arus terhubung dengan pin A2 pada arduino mega 2560.

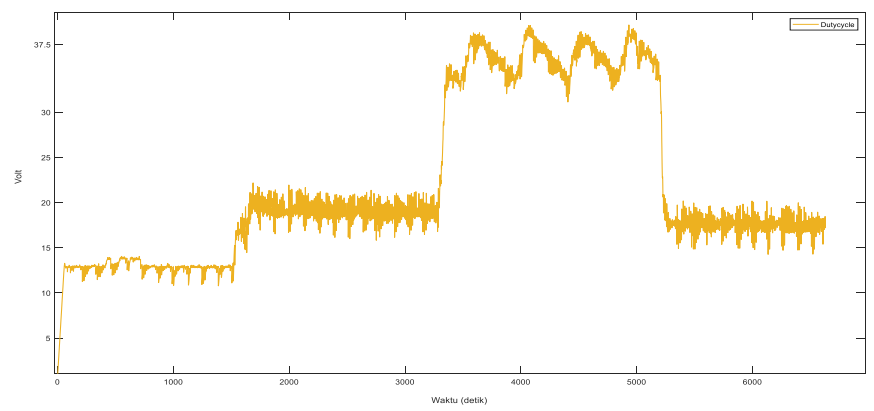

Gambar 14. Nilai duty cycle saat tegangan bevariasi

Dari gambar 14 dapat dinyatakan bawa nilai duty cycle mengikuti tegangan yang ada pada gambar 12 dapat dilihat saat nilai duty cycle $20 \%$ ketika nilai tegangan output 45volt dan nilai duty akan naik jika tegangan output juga naik begitu juga sebaliknya, dapat dilihat nilai duty cycle $37 \%$ pada saat tegangan output 83 volt dan nilai duty cycle $18 \%$ pada saat tegangan output $35 \mathrm{volt}$. Hal ini karena nilai duty cycle akan semakin tinggi jika perbandingan tegangan output dan tegangan referensi terlalu jauh.

\section{Penutur}

sistem kendali DC chopper menggunakan arduino yang diprogram menggunakan simulink Matlab. DC choper satu kuadran dibuat dengan tegangan masukkan 150 Volt dengan tegangan output yang bervariasi. DC chopper satu kuadran di uji dengan beban sebuah resistor dengan tegangan bervariasi mulai dari 35 volt hingga 83 volt. Hasil pengujian menunjukan bahwa DC chopper satu kuadran telah bekerja sesuai dengan harapan, dimana tegangan output yang dihasilkan sudah sesuai dengan tegangan referensi yang diberikan. Penelitian ini dapat dikemangkan dengan metode control yang berebda-beda dan juga beban yang berbeda-beda pula.

\section{REFERENSI}

[1] Nagarajan, Dr R., et al. "Chopper fed speed control of DC motor using PI controller." IOSR-Journal of Electrical and Electronics Engineering (IOSRJEEE) 11.3 (2016): 65-69.

[2] Muhammad H. Rashid, Power Electronics Handbook. 2011.

[3] Yusmartato, "Perancangan Alat Pengaturan Kecepatan Motor DC Shunt Menggunakan Rangkaian DC Chopper Berbasis Komputer", Journal of Eletrical Technology, vol. 1, no. 1, 2016.

[4] Arguta, Chardian, Sulastri Rubiyanti, Eko Sulistyo. "Kontrol Kecepatan Motor DC Dengan Kontrol PID Berbasis Mikrokontroller ATmega 8535". (2017).

[5] A. Naik and A. Ravichandran. "Analyzing Speed Control of Chopper Fed DC Drive Using Open and 
Closed Loop Techniques, Indian Journal of Applied Research, vol.5, no. 9, p. 58, Sept 2015.

[6] C. R. Harahap, "Perancangan Alat Pratikum Klasifikasi DC Choper Pada Labor Konversi Energi Elektrik", Jurnal Rekayasa dan Teknologi Elektro, vol.3, no 03, p.151, 2011.

[7] M. I. Esario and M. Yuhendri, "Kendali Kecepatan Motor DC Menggunakan DC Chopper Satu Kuadran Berbasis Kontroller PI," JTEV, vol. 06, no. 01, pp. 296305, 2020.

[8] C. K. Das and S. K. Swain, "Closed Loop Speed Control Of Chopper Fed DC Motor For Industrial Drive Application", International Conference on Power and Embedded Drive Control (ICPEDC), Department of Electrical and Electronics Engineering, Birla Institute of technology, Ranchi, India, 2017.

[9] A. Anggawan and M. Yuhendri, "Implementasi kendali tegangan output buck converter berbasis Simulink Matlab, Jurnal Teknik Elektro Indonesia, vol. 2, pp. 3439, 2021.

[10] A. Aswaldi and M. Yuhendri, "Sitem Kendali dan Monitoring Boost Converter Berbasis GUI (Graphical User Interface) Matlab Menggunakan Arduino", JTEIN, vol. 1, no 2, pp.266-272, 2020.

[11] V. Viswanatha and R.V.S. Reddy, "Digital Control of Buck Converter Using Arduino Microcontroller For Low Power Applications", in Proc. 2017 SmartTechCon, pp. 439-443,17-19 Aug 2017.

[12] R. R. Bonert, "Automatic Speed Control of OneQuadrant DC Drives", IEEE TRANSACTIONS ON INDUSTRY APPLICATIONS, Vol. IA-18, No. 5, Sept 1982.
[13] M. R. Crapsiz, B. Alim and H Kavehci. "Detailed Analysis of DC Choppers and An Example of PMDC Motor Speed Control", Eastern Anatolian Journal of Science, vol. 4, no. 1, pp. 16-36, 2018.

[14] Sahana, M., Sachin Angadi, and A. B. Raju. "Speed control of separately excited DC motor using class a chopper." 2016 International Conference on Circuits, Controls, Communications and Computing (I4C). IEEE, 2016.

[15] Aswardi, M. Yuhendri dan D. T. Yanto, Teknik Elektronika Daya, Indonesia : IRDH Book Publisher, 2020.

\section{Biodata Penulis}

Azar Ihsan, lahir di Bukittinggi, 15 April 1996. Menyelesaikan Sarjana Terapan di bidang Teknik Elektro Industri pada Jurusan Teknik Elektro FT UNP.

Muldi Yuhendri, dilahirkan di Agam pada tanggal 13 Desember 1981. Menyelesaikan program Sarjana di jurusan teknik elektro Universitas Negeri Padang pada tahun 2005 dan Program S2 di ITS Surabaya pada tahun 2009 serta S3 Ilmu Teknik Elektro pada tahun 2017 di kampus yang sama. Bekerja sebagai staf pengajar di jurusan teknik elektro Universitas Negeri Padang sejak tahun 2006 sampai sekarang, 